\title{
Study of the Expression of ALDH1 and CD44 Stem Cell Markers in Male Breast Cancers
}

\author{
Ping Gong ${ }^{1 *}$, Bruce Boman², Juan Palazzo ${ }^{1}$ \\ ${ }^{1}$ Department of Pathology, Anatomy and Cell Biology, Thomas Jefferson University Hospital, Philadelphia, USA; ${ }^{2}$ Cancer Genetics \\ and Stem Cell Biology, Helen F. Graham Cancer Center, Christiana Care Health Services, Newark, USA. \\ Email: *gping007@hotmail.com
}

Received June $19^{\text {th }}, 2013$; revised July $19^{\text {th }}, 2013$; accepted July $29^{\text {th }}, 2013$

Copyright (C) 2013 Ping Gong et al. This is an open access article distributed under the Creative Commons Attribution License, which permits unrestricted use, distribution, and reproduction in any medium, provided the original work is properly cited.

\begin{abstract}
Aims: Male breast cancer represents $<1 \%$ of all breast cancers. Cancer stem cell (CSC)s have been associated with tumor aggressiveness and drug resistance. CSCs are characterized by CD44 and/or ALDH1 expression. In this study, we investigated their expression in male breast cancer. Method: Two in situ ductal carcinoma (DCIS) and 18 invasive ductal carcinoma (IDC) male breast cancer cases were studied with Jefferson IRB approval. Membrane staining of CD44 was scored by the percentage of positivity. Cytoplasmic expression of ALDH1 was considered positive. Results: Ten cases had high CD44 expression, which were all IDC. Both DCIS and in situ component of IDC were CD44 low. ALDH1 was only positive in 15 IDCs. ALDH1+ cells were mostly in the invasive component. Both DCIS cases were negative for ALDH1. Among the 15 ALDH1+ IDCs, five with only invasive component had a higher percentage (average $4.4 \%$ ) of positive cells compared to the other eight with in situ components (average $2.0 \%$ ). Metastatic cells in sentinel lymph nodes had a similar expression pattern of CD44 and ALDH1 as their primary tumor. Conclusion: CD44 and ALDH1 are expressed in male breast cancers and they are overexpressed in invasive cancer compared to carcinoma in situ. These findings suggest that CSCs play an important role in the progression to invasive carcinoma.
\end{abstract}

Keywords: Male Breast Cancer; Cancer Stem Cell; CD44; ALDH1

\section{Introduction}

Male breast cancer is a rare disease that represents $<1 \%$ of all breast cancer diagnoses [1]. However, the mortality is $31 \%$, which is considerably higher than for breast cancer in women [2]. Male breast cancer is usually detected at a more advanced stage than female breast cancer [3].

Male breast cancer is biologically different from female breast cancer. Pathologically, the vast majority of male breast cancers are invasive ductal carcinomas (IDCs) [4]. The lobular histotype accounts for only $1.5 \%$ of invasive carcinoma. Also, a higher percentage of male breast carcinomas than female breast carcinomas are estrogen receptor and progesterone receptor positive [5]. The HER2/neu allele is less likely to be present in male breast cancers [6].

More recently, cancer stem cells (CSCs) have been implicated in the development of solid tumors including breast cancers [7]. Moreover, CSCs, which have the abil-

${ }^{*}$ Corresponding author. ity to both self renew and give rise to differentiated progeny, have been implicated in the mechanisms of cancer resistance to chemotherapy and radiation [7]. The status of CSCs in tumors has therefore become of keen interest. Therefore, development of markers for SCs and CSCs has gained increased attention.

Previous studies suggest that stem cell-like populations in normal female breast tissue are characterized by the expression of aldehyde dehydrogenase 1 (ALDH1). ALDH1, an enzyme responsible for oxidation of retinol to retinoic acid, is important for normal development and homoeostasis in several organs and is crucial during embryogenesis $[8,9]$. Breast cancer stem cells also express ALDH1 and breast CSCs have been isolated on the basis of increased ALDH1 [10]. Indeed, expression of ALDH1 by breast tissue is considered to be a marker, in breast, for both normal and malignant stem and progenitor cells. This finding appears to be clinically important as ALDH1 expression has been associated with poor clinical outcome and resistance to chemotherapy in female breast cancers [10]. 
Breast cancer cells with a CD44+/CD24- phenotype have also been suggested to have tumor-initiating properties with stem cell-like features and have been shown to be associated with basal-like cancers and BRCA1 hereditary breast cancers in women [11]. The recent study showed increased invasion and tumorigenicity capacity of CD44+/CD24- breast cancer MCF7 cells in vitro and in nude mice [12]. A partial overlap between the CD44+/ CD24-/low population and the ALDH1+ population has been reported. The combined CD44+/ALDH1+ phenotype shows an especially high tumorigenic capacity, being able to form tumors in nude mice from as few as 20 transplanted cells [10]. In this study, we are going to use CD44 and ALDH1 as cancer stem cell marker.

The tumor microenvironment also affects cancer development and plays a significant role in prognosis. This appears to be true for the effect of stem/progenitor cells on the prognosis of human breast tumors. Stromal cells of breast tumors have been shown to be positive for ALDH1 [13].

Several studies have investigated the correlation between the expression of CSC markers and prognosis and drug resistance in female breast cancer. However, the expression of CSC markers in male breast cancer has not been well studied. Accordingly, in this study, we analyzed the expression of two CSC markers-ALDH1 and CD44 - in 19 male breast cancers.

\section{Materials and Methods}

Approval of the study protocol was obtained from the Jefferson Internal Review Board. All the male breast cancers were obtained from the files of the Department of Pathology of Thomas Jefferson University Hospital diagnosed between 1982 and 2012. A total of 20 cases were reviewed to confirm the diagnosis and to pathologically characterize each tumor. The following information was obtained in each case: patient age, tumor subtype, size, nuclear and histological grade, and ER and PR status. The 20 cases included 2 ductal carcinomas in situ (DCISs) and 18 invasive ductal carcinomas (IDCs).

Immunohistochemical staining was done using formalin-fixed, paraffin-embedded $4 \mu \mathrm{m}$ sections. Representative sections were stained with antibodies against both CD44 (Clone 156-3C11, 1:800 dilution, Thermo Scientific, Fremont, CA) and ALDH1 (1:100 dilution, BD Bioscience, San Jose, CA]. Staining procedures followed previously published protocols [13-15]. Specificity of staining was confirmed by positive controls (liver for ALDH1 and tonsil for CD44) and negative controls (replacement of the primary antibody by PBS).

CD44 staining was detected mainly on the cell membrane and was scored by the percentage of tumor cells that were positive for the stain $(0 \%, 0 \%$ positive tumor cells; $1 \%, 1 \%$ to $10 \%$ positive cells; $2 \%, 11 \%$ to $50 \%$ positive cells; $3 \%, 51 \%$ to $75 \%$ positive cells; $4 \%, 76 \%$ to $100 \%$ positive cells) [16]. Tumors with scores 1 and 2 were defined as tumors with low CD44 expression and tumors with scores 3 and 4 were defined as having high CD44 expression. The percentage of cells exhibiting cytoplasmic expression of ALDH1 in tumor cells was recorded. Since no consensus exists for ALDH1 scoring based on the percentage of cells, any tumor cell with detectable staining according to previous studies [13-15] was considered positive. We also recorded the percentage of tumor cells that were positive.

We also analyzed the cytoplasmic expression of ALDH1 in stromal cells. The presence of $>5 \%$ ALDH1 positive cells in the stroma was defined as high expression.

\section{Results}

Two of the 20 cases $(10 \%)$ were pure in situ ductal carcinomas, whereas the other 18 cases $(90 \%)$ were invasive ductal carcinomas with or without an in situ component. Table 1 lists the following information of the 20 patients: the diagnosis, age, tumor size, nuclear grade, histologic grade, the percentage of CD44 positive and ALDH1 positive tumor cells, ALDH1 staining in tumor stroma, ALDH1 staining score, lymph node metastasis, and ER and PR expression. Tumor size ranged from 0.7 to 6.0 $\mathrm{cm}$.

Ten of 20 cases $(50 \%)$ had high CD44 expression (70\% - 100\% CD44+ cells in tumors), which were all IDCs (Figure 1). Both DCIS cases had low CD44 expression $(30 \%-40 \%$ of tumor cells were positive) (Figure 2). Of the 18 IDC cases, 13 cases also had an in situ component (Table 2). Interestingly, 11 of 13 (84.6\%) of the in situ components in the invasive cases had low CD44 expression. Only two cases showed increased CD44 expression in the in situ components of the tumor. However, among the invasive components of the 18 IDC cases, 11 showed high CD 44 expression. Overall, CD44 expression was low in DCIS and in the in situ component of IDCs; IDCs tended to have higher CD44 expression than DCISs, especially in the invasive component.

ALDH1 expression in tumor cells showed wide variation among our cases, ranging from negative to a low level $(1 \%-5 \%)$ to a high level $(5 \%-10 \%)$. ALDH1 expression in tumors was positive in 15 of 20 (75\%) cases, all of which were IDCs (Table 3). Both DCIS cases were negative for ALDH1 expression (Figure 3). Fifteen of 18 (83.3\%) IDCs were positive for ALDH1 (Figure 4). Among the 15 ALDH1+ IDC cases, five had only an invasive component and nine had both invasive and in situ components. Only two cases were positive for ALDH1 expression in their in situ component. The other 12 cases were positive for ALDH1 expression in the invasive component. The five IDC cases with only an invasive 
Table 1. Pathological and immunohistochemical features of all male breast cancers in the study.

\begin{tabular}{|c|c|c|c|c|c|c|c|c|c|c|c|c|}
\hline Number & DX & Age & Size & $\mathrm{Ng}$ & Hg & CD44 & ALDH1/Tumor & ALDH1/Stroma & LN met & ALDH1 & ER & PR \\
\hline 1 & IDC & 89 & $\mathrm{n} / \mathrm{a}$ & II & III & $>90$ & 0 & low & $2 / 19$ & 0 & $\mathrm{n} / \mathrm{a}$ & $\mathrm{n} / \mathrm{a}$ \\
\hline 2 & IDC & 86 & $6 \mathrm{~cm}$ & III & III & $>90$ & 1 & low & & 1 & + & + \\
\hline 3 & IDC & 83 & $2.5 \mathrm{~cm}$ & II & III & $10 \%-20 \%$ & 5 & high & & 1 & $70 \%-80 \%$ & $<10 \%$ \\
\hline 4 & IDC & 79 & $2.5 \mathrm{~cm}$ & II & II & 25 & $3 \%$ & high & & 1 & $0 \%$ & $90 \%$ \\
\hline 5 & IDC & 69 & $2 \mathrm{~cm}$ & III & II & 30 & $3 \%$ & low & $4 / 7$ & 1 & $90 \%$ & $5 \%$ \\
\hline 6 & DCIS & 45 & $0.7 \mathrm{~cm}$ & III & $\mathrm{n} / \mathrm{a}$ & 40 & 0 & high & & 0 & $70 \%-90 \%$ & $70 \%-90 \%$ \\
\hline 7 & IDC & 67 & $1.1 \mathrm{~cm}$ & II & II & 90 & 1 & high & & 1 & $90 \%$ & $75 \%$ \\
\hline 8 & IDC & 72 & $1.0 \mathrm{~cm}$ & II & II & 100 & $5 \%$ & high & & 1 & $90 \%$ & $85 \%$ \\
\hline 9 & IDC & 76 & $0.7 \mathrm{~cm}$ & II & II & 80 & 0 & high & & 0 & $70 \%$ & $60 \%$ \\
\hline 10 & DCIS & 57 & $3 \mathrm{~cm}$ & I & $\mathrm{n} / \mathrm{a}$ & 30 & 0 & low & $1 / 21$ & 0 & $100 \%$ & $100 \%$ \\
\hline 11 & IDC & 79 & $3 \mathrm{~cm}$ & II & II & 100 & 1 & high & & 1 & $\mathrm{n} / \mathrm{a}$ & $\mathrm{n} / \mathrm{a}$ \\
\hline 12 & IDC & 67 & $0.7 \mathrm{~cm}$ & II & II & 70 & $5 \%$ & low & & 1 & negative & negative \\
\hline 13 & IDC & 92 & $\mathrm{n} / \mathrm{a}$ & III & III & 20 & 1 & high & & 1 & $\mathrm{n} / \mathrm{a}$ & $\mathrm{n} / \mathrm{a}$ \\
\hline 14 & IDC & 105 & $\mathrm{n} / \mathrm{a}$ & & & 20 & 0 & low & & 0 & $\mathrm{n} / \mathrm{a}$ & $\mathrm{n} / \mathrm{a}$ \\
\hline 15 & IDC & 63 & $0.7 \mathrm{~cm}$ & II & I & 90 & $10 \%$ & high & & 1 & $100 \%$ & $90 \%$ \\
\hline 16 & IDC & 56 & $2 \mathrm{~cm}$ & II & II & 95 & $5 \%$ & high & & 1 & $90 \%$ & $85 \%$ \\
\hline 17 & IDC & 79 & $\mathrm{n} / \mathrm{a}$ & & & 10 & 0 & low & & 1 & $\mathrm{n} / \mathrm{a}$ & $\mathrm{n} / \mathrm{a}$ \\
\hline 18 & IDC & 83 & $\mathrm{n} / \mathrm{a}$ & I & II & 100 & $1 \%$ & high & & 1 & 90 & 90 \\
\hline 19 & IDC & 73 & $1.3 \mathrm{~cm}$ & II & III & $>90$ & $2 \%$ & High & $0 / 5$ & 1 & $90 \%$ & $90 \%$ \\
\hline 20 & IDC & 69 & $0.8 \mathrm{~cm}$ & II & I & 10 & $1 \%$ & Low & & 1 & $93 \%$ & $96 \%$ \\
\hline
\end{tabular}

DCIS $=$ ductal carcinoma in situ; IDC $=$ invasive ductal carcinoma; $\mathrm{DX}=$ diagnosis.

Table 2. CD44 expression in different subtypes of male breast cancer.

\begin{tabular}{cccc}
\hline & CD44 expression & \\
\hline DCIS & High & Low & Total \\
IDC & 0 & 2 & 2 \\
Invasive component & 11 & 7 & 18 \\
In situ component & 2 & 7 & 18 \\
\hline
\end{tabular}

Table 3. ALDH1 expression in the tumor and stroma of different subtypes of male breast cancer.

\begin{tabular}{|c|c|c|c|c|}
\hline & \multicolumn{2}{|c|}{$\begin{array}{l}\text { ALDH tumor } \\
\text { expression }\end{array}$} & \multicolumn{2}{|c|}{ ALDH stromal expression } \\
\hline & Positive & Negative & Low & High \\
\hline DCIS & 0 & 2 & 1 & 1 \\
\hline IDC & 15 & 3 & 7 & 11 \\
\hline Invasive only & 5 & 0 & & \\
\hline $\begin{array}{l}\text { In situ and invasive } \\
\text { component }\end{array}$ & 10 & 3 & & \\
\hline Total & 15 & 5 & 8 & 12 \\
\hline
\end{tabular}

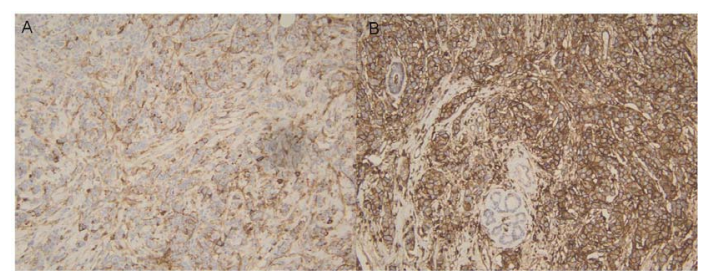

Figure 1. Invasive ductal carcinoma with low (A) and high (B) CD44 expression (Immunohistochemical stain, original magnification $\times 200$ ).

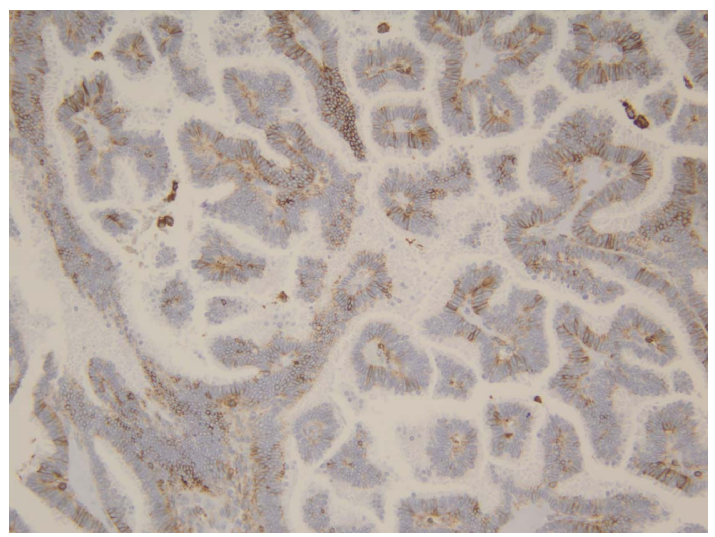

Figure 2. Ductal carcinoma in situ with low CD44 expression (Immunohistochemical stain, original magnification $\times 200)$. 


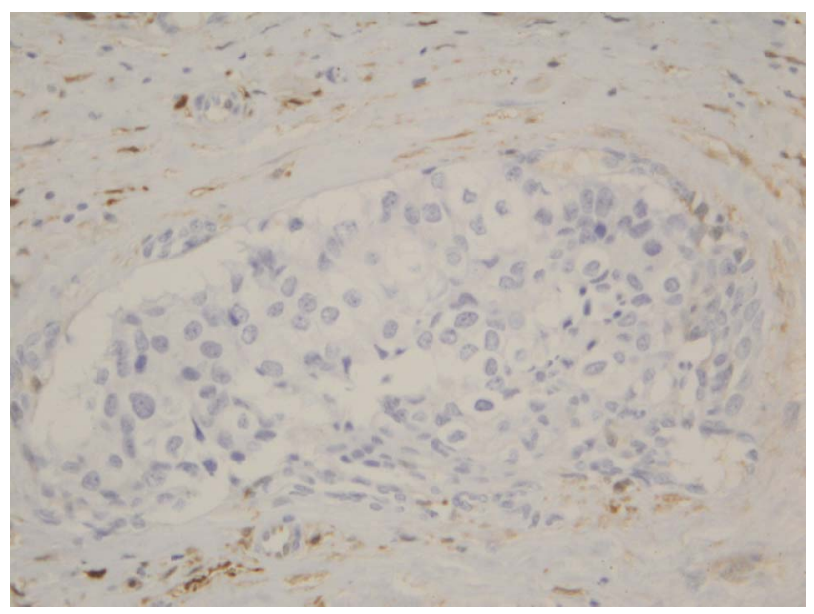

Figure 3. Ductal carcinoma in situ with negative ALDH1 expression (Immunohistochemical stain, original magnification $\times 200)$.

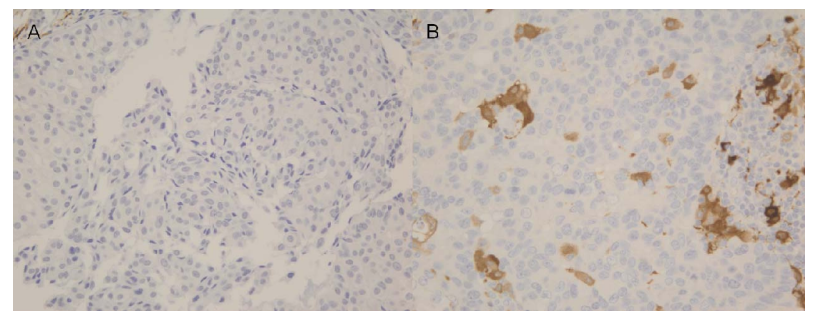

Figure 4. Invasive ductal carcinomas with negative $(A)$ and positive (B) ALDH1 expression (Immunohistochemical stain, original magnification $\times 200$ ).

component had a higher percentage $(1 \%-10 \%$, average $4.4 \%$ ) of ALDH1 positive cells in their tumors compared to the other ten ALDH1+ IDC cases with in situ components $(1 \%-5 \%$, average $2.0 \%)$. ALDH1+ CSCs were present in IDCs, especially the invasive component, but were absent in DCIS. ALDH1 expression was higher in IDCs that have only an invasive component compared to IDCs with an in situ component.

Three cases had sentinel lymph node metastases at the time of surgery. We were able to perform the staining in only one of the positive lymph nodes (case \#1). These metastatic cells had similar expression patterns of CD44 and ALDH1 compared to the primary tumor: high CD44 expression and negative ALDH1 expression. The other two cases with metastases in the lymph nodes showed variable ALDH1 staining and low CD44 expression in the primary tumors.

We also found that stromal cells in the region of the tumors and within the tumors were positive for ALDH1. Eight cases had low ALDH1 stromal expression, while the other 12 cases had high stromal expression, of which 11 were IDCs, and 1 was a DCIS. Stromal expression of ALDH1 in male breast cancer did not show any correlation with prognosis.

\section{Discussion}

Stem cell (SCs) is cells that have the ability to perpetuate themselves through self-renewal and to generate mature cells of a particular tissue through differentiation [7]. Cancer stem cells (CSCs), akin to normal stem cells, are postulated to have the ability to self renew and give rise to differentiated progeny. It has been shown that solid cancers are comprised of a heterogeneous population of cells that differ in morphology, marker expression, proliferation capacity, and tumorigenicity [7,17]. Two general models of heterogeneity are proposed: 1) cancer cells of many different phenotypes have the potential to proliferate extensively, but any one cell would have a low probability of exhibiting this potential in an assay of clonogenicity or tumorigenicity; 2) Most cancer cells have only limited proliferative potential, but a subset of cancer cells (i.e. CSCs) consistently proliferate extensively in clonogenic assays and can form new tumors when transplanted. The CSC concept provides an explanation for the limitations of current cancer treatment-it is designed to target rapidly dividing cells, not the relatively quiescent CSCs. If we could better understand how CSCs drive tumor growth, we could develop ways to target CSCs, which would suggest new strategies for cancer prevention and therapy $[7,17,18]$.

Progress in the field of SC biology has been long hampered by difficulties in identifying, isolating, and characterizing SCs until SC markers were identified. The CSCs and the tumors they form demonstrate the capacity for serial passage in immunocompromised mice and for differentiation into multiple cell lineages resembling the original tumor [18-20]. For example, CSCs isolated using ALDH1+/CD44+/CD24- markers from breast cancers were able to generate tumors in immunocompromised mice with as few as 20 cells [10]. In addition to the studies of CSCs in breast tissue, ALDH1+ CSCs have also been shown to contribute to colon tumorigenesis [21]. Since ALDH1 and CD44 have been well established as cancer stem cell markers in breast cancer, we are using these two markers to study the role of cancer stem cell in male breast cancer.

CSCs are thought to play a role not only in initiation but also progression and recurrence of cancer. CSC studies of female breast cancers have shown that expression of SC markers is associated with aggressive phenotypes such as high histologic grade, the absence of ER or PR positivity, and HER2 overexpression [22]. CSCs are also increased in metastatic sites [23].

Little is known about CSCs in male breast cancer because it is an uncommon disease and not frequently studied. We found that in male breast cancers, ALDH1 is positive in IDCs but not DCISs. CD44 expression is low in DCISs and in the in situ component of IDCs, but high in the invasive components of IDCs. Lymph node metastases appeared to show a similar expression pattern 
compared to their primary tumors.

The fact that positivity for CD44 and ALDH1 tended to be low in DCISs and high in IDCs suggests that CSCs become overpopulated during the progression to invasive cancer. Our findings on expression of CSC markers in male breast cancers are similar to those known for female breast cancers [10]. Given that CSC overpopulation may be responsible for progression to invasive male breast cancer; this suggests that CSCs are prime targets for anticancer therapy. This view is consonant with ideas on new treatment approaches for female breast cancers [18,21].

Male and female breast cancers differ in histological subtype [3]. There are also differences at the molecular level. In our previous studies, we found that, compared to female breast cancers, male breast cancers have a specific miRNA expression signature [17] with significantly dysregulated miRNA: 4 overexpressed and 13 underexpressed) [24]. The targets of these miRNA genes include HOXD10 and VEGF, which may be directly involved in male breast cancer development [24]. Additionally, the cytokeratin profiles of male breast cancer demonstrate that male breast cancers have a similar frequency of basal-like phenotype to that of female breast cancers. The expression of CK5/6 and CK14 identifies a subset of pathologically aggressive male breast cancers [25].

ALDH1 expression is found not only in breast carcinoma cells, but also, has been detected in stromal cells. Stromal expression of ALDH1 in female breast cancer was predictive of disease-free survival in triple negative tumors [13]. This would indicate that the tumor microenvironment might play a role in determining the prognostic impact of cancer stem cells. However, male breast cancers are usually not triple negative tumors. We only had 3 cases with metastasis to the lymph nodes, and there were not any differences in ALDH1 expression between stromal and epithelial tumor tissues compared to cases without lymph node metastases.

There have been conflicting reports about the correlation between CSC marker expression and long term prognosis in female breast cancers $[13,18,26]$. Recent studies showed positive association between ALDH1 expression and prognosis in node positive female breast cancers [26]. The ALDH1 phenotype is an independent predictor of early tumor relapse [27]. In our study of male breast cancer patients, we did not find expression of two CSC markers, CD44 and ALDH1, to correlate with a number of prognostic parameters, such as tumor size, lymph node metastasis, and nuclear and histologic grading. A limitation of our study includes the lack of longterm follow-up of these patients and the number of metastatic tumors that we were able to analyze.

\section{Conclusion}

In summary, in this pilot study we show that CD44 and
ALDH1 are expressed in male breast cancers and they are overexpressed in invasive cancer compared to carcinoma in situ. These findings suggest that CSCs play an important role in the progression to invasive carcinoma. Interestingly, we find low expression of stromal cells in patients with metastatic disease.

\section{REFERENCES}

[1] I. S. Fentiman, A. Fourquet and G. N. Hortobagyi, "Male Breast Cancer," Lancet, Vol. 367, No. 9510, 2006, pp. 595-604. http://dx.doi.org/10.1016/S0140-6736(06)68226-3

[2] W. L. Donegan, P. N. Redlich, P. J. Lang and M. T. Gall, "Carcinoma of the Breast in Males. A Multiinsititutional Survey," Cancer, Vol. 83, No. 3, 1998, pp. 498-509. http://dx.doi.org/10.1002/(SICI)1097-0142(19980801)83: 3<498::AID-CNCR19>3.0.CO;2-R

[3] L. Ottini, D. Palli, S. Rizzo, M. Federico, V. Bazan and A. Russo, "Male Breast Cancer," Critical Review in Oncology Hematology, Vol. 73, No. 2, 2010, pp. 141-155. http://dx.doi.org/10.1016/j.critrevonc.2009.04.003

[4] S. H. Giordano, D. S. Cohen, A. U. Buzdar, et al., "Breast Carcinoma in Men: A Population-Based Study," Cancer, Vol. 101, No. 1, 2004, pp. 51-57. http://dx.doi.org/10.1002/cncr.20312

[5] W. F. Anderson, M. D. Althuis, L. A. Brinton and S. S. Devesa, "Is Male Breast Cancer Similar or Different than Female Breast Cancer?" Breast Cancer Research and Treatment, Vol. 83, No. 1, 2004, pp. 77-86. http://dx.doi.org/10.1023/B:BREA.0000010701.08825.2d

[6] K. J. Bloom, H. Govil, P. Gattuso, et al., "Status of HER2 in Male and Female Breast Carcinoma," American Journal of Surgery, Vol. 182, No. 4, 2001, pp. 389-392. http://dx.doi.org/10.1016/S0002-9610(01)00733-4

[7] T. Reya, S. J. Morrison, M. F. Clarke and I. L. Weissman, "Stem Cells, Cancer, and Cancer Stem Cells," Nature, Vol. 414, 2001, pp. 105-111. http://dx.doi.org/10.1038/35102167

[8] G. Duester, "Families of Retinoid Dehydrogenases Regulating Vitamin A Function: Production of Visual Pigment and Retinoic Acid," European Journal of Biochemistry, Vol. 267, No. 14, 2000, pp. 4315-4324. http://dx.doi.org/10.1046/j.1432-1327.2000.01497.x

[9] A. M. Simeone and A. M. Tari, "How Retinoids Regulate Breast Cancer Cell Proliferation and Apoptosis," Cellular and Molecular Life Sciences, Vol. 61, No. 12, 2004, pp. 1475-1484. http://dx.doi.org/10.1007/s00018-004-4002-6

[10] C. Ginestier, M. H. Hur, E. Charafe-Jauffret, F. Monville, J. Dutcher, M. Brown, J. Jacquemier, P. Viens, C. G. Kleer, S. Liu, A. Schott, D. Hayes, D. Birnbaum, M. S. Wicha and G. Dontu, "ALDH1 Is a Marker of Normal and Malignant Human Mammary Stem Cells and a Predictor of Poor Clinical Outcome," Cell Stem Cell, Vol. 1, No. 5, 2007, pp. 555-567. http://dx.doi.org/10.1016/j.stem.2007.08.014

[11] G. Honeth, P. O. Bendahl, M. Ringner, L. H. Saal, S. K. Gruvberger-Saal, K. Lovgren, D. Grabau, M. Ferno, A. 
Borg and C. Hegardt, "The CD44+/CD24- Phenotype Is Enriched in Basal-Like Breast Tumors," Breast Cancer Research, Vol. 10, 2008, p. R53. http://dx.doi.org/10.1186/bcr2108

[12] W. Yan, Y. Chen, Y. Yao, H. Zhang and T. Wang, "Increased Invasion and Tumorigenicity Capacity of CD44+/ CD24- Breast Cancer MCF7 Cells in Vitro and in Nude Mice," Cancer Cell International, Vol. 13, No. 1, 2013, p. 62. http://dx.doi.org/10.1186/1475-2867-13-62

[13] E. Resetkova, J. S. Reis-Filho, R. K. Jain, R. Mehta, M. A. Thorat, H. Nakshatri and S. Badve, "Prognostic Impact of ALDH1 in Breast Cancer: A Story of Stem Cells and Tumor Microenvironment," Breast Cancer Research and Treatment, Vol. 123, No. 1, 2010, pp. 109-111. http://dx.doi.org/10.1007/s10549-009-0619-3

[14] V. Neumeister, S. Agarwal, J. Bordeaux, R. L. Camp and D. L. Rimm, "In Situ Identification of Putative Cancer Stem Cells by Multiplexing ALDH1, CD44, and Cytokeratin Identifies Breast Cancer Patients with Poor Prognosis," American Journal of Pathology, Vol. 176, 2010, pp. 2131-2138. http://dx.doi.org/10.2353/ajpath.2010.090712

[15] H. Nalwoga, J. B. Arnes, H. Wabinga and L. A. Akslen, "Expression of Aldehyde Dehydrogenase I (ALDH1) Is Associated with Basal-Like Marders and Features of Aggressive Tumours in African Breast Cancer," British Journal of Cancer, Vol. 102, 2010, pp. 369-375. http://dx.doi.org/10.1038/sj.bjc.6605488

[16] M. Fernandez-Figueras, L. Puig, A. Ariza, A. Calatrava, M. Feunte and C. Ferrandiz, "CD44 Distribution in Sweet Gland Tumors Suggests It Has Different Functional Roles in the Various Cell Types," American Journal of Dermatopathology, Vol. 18, No. 5, 1996, pp. 483-489. http://dx.doi.org/10.1097/00000372-199610000-00007

[17] K. Polyak, "Breast Cancer: Origins and Evolution," Journal of Clinical Investigation, Vol. 117, No. 11, 2007, pp. 3155-3163. http://dx.doi.org/10.1172/JCI33295

[18] M. Kakarala and M. S. Wicha, "Implications of the Cancer Stem-Cell Hypothesis for Breast Cancer Prevention and Therapy," Journal of Clinical Oncology, Vol. 26, No. 17, 2008, pp. 2813-2820. http://dx.doi.org/10.1200/JCO.2008.16.3931

[19] T. Lapidot, C. Sirard, J. Vormoor, et al., "A Cell Initiating Human Acute Myeloid Leukemia after Transplantation into SCID Mice," Nature, Vol. 367, 1994, pp. 645648. http://dx.doi.org/10.1038/367645a0

[20] B. M. Boman and M. S. Wicha, "Cancer Stem Cells: A
Step toward the Cure," Journal of Clinical Oncology, Vol. 26, No. 17, 2008, pp. 2795-2799.

http://dx.doi.org/10.1200/JCO.2008.17.7436

[21] E. Huang, M. J. Hynes, T. Zhang, C. Ginestier, G. Dontu, H. Appelman, J. Z. Fields, M. S. Wicha and B. M. Boman, "Aldehyde Dehydrogenase 1 Is a Marker for Normal and Malignant Human Colonic Stem Cells (SC) and Tracks SC Overpopulation during Colon Tumorigenesis," Cancer Research, Vol. 69, 2009, pp. 3382-3389. http://dx.doi.org/10.1158/0008-5472.CAN-08-4418

[22] K. Morimoto, S. J. Kim, T. Tanei, K. Shimazu, Y. Tanji, T. Taguchi, Y. Tamaki, N. Terada and S. Noguchi, "Stem Cell Marker Aldehyde Dehydrogenase 1-Positive Breast Cancers Are Characterized by Negative Estrogen Receptor, Positive Human Epidermal Growth Factor Receptor Type 2, and High Ki67 Expression," Cancer Science, Vol. 100, 2009, pp. 1062-1068. http://dx.doi.org/10.1111/j.1349-7006.2009.01151.x

[23] M. Balic, H. Lin, L. Young, et al., "Most Early Disseminated Cancer Cells Detected in Bone Marrow of Breast Cancer Patients Have a Putative Breast Cancer Stem Cell Phenotype," Clinical Cancer Research, Vol. 12, 2006, pp. 5615-5621. http://dx.doi.org/10.1158/1078-0432.CCR-06-0169

[24] M. Fassan, R. Baffa, J. P. Palazzo, J. Lloyd, M. Crosariol, C. Liu, S. Volinia, H. Alder, M. Rugge, C. M. Croce and A. Rosenberg, "MicroRNA Expression Profiling of Male Breast Cancer," Breast Cancer Research, Vol. 11, 2009, p. R58. http://dx.doi.org/10.1186/bcr2348

[25] V. Ciocca, A. Bombonati, Z. Gatalica, M. D. Pasquale, A. Milos, A. Ruiz-Orrico, D. Dreher, N. Folch, F. Monzon, G. Santeusanio, C. M. Perou, P. S. Bernard and J. P. Palazzo, "Cytokeratin Profiles of Male Breast Cancers," Histopathology, Vol. 49, 2006, pp. 365-370. http://dx.doi.org/10.1111/j.1365-2559.2006.02519.x

[26] T. Yoshioka, Y. Umekita, Y. Ohi, M. Souda, Y. Sagara, Y. Sagara, Y. Sagara, Y. Rai and A. Tanimoto, "Aldehyde Dehydrogenase 1 Expression Is a Predictor of Poor Prognosis in Node-Positive Breast Cancers: A Long Term Follow-Up Study," Histopathology, Vol. 58, No. 4, 2011, pp. 608-616. http://dx.doi.org/10.1111/j.1365-2559.2011.03781.x

[27] Y. Zhong, Y. Lin, S. Shen, Y. Zhou, F. Mao, J. Guan and Q. Sun, "Expression of ALDH1 in Breast Invasive Ductal Carcinoma: An Independent Predictor of Early Tumor Relapse," Cancer Cell International, Vol. 13, No. 1, 2013, p. 60. http://dx.doi.org/10.1186/1475-2867-13-60 